\title{
The Role of Specialisation in the Promotion of Young Football Talents: A Person-Oriented Study
}

Marc Zibung \& Achim Conzelmann

European Journal of Sport Science (EJSS)

Corresponding author:

Marc Zibung

University of Bern

Bremgartenstrasse 145

$\mathrm{CH}-3012$ Bern

Tel. +41316315658

marc.zibung@ispw.unibe.ch
Prof. Dr. Achim Conzelmann

University of Bern

Bremgartenstrasse 145

$\mathrm{CH}-3012$ Bern

Tel. +41316318322

achim.conzelmann@ispw.unibe.ch 


\section{Abstract}

This paper investigates the controversial question whether it is more effective to promote specialisation in a specific sport at the beginning of a career, or whether to encourage a broad range of sports when promoting competitive sports talents in order for them to achieve a high level of performance in adulthood. The issue of promoting talents depends on human developmental processes and therefore raises developmental scientific questions. Based on recent, dynamic-interactionist concepts of development, we assume a person-oriented approach focussing on the person as a whole rather than individual features. Theoretical considerations lead to four interacting factors being summarised to form a subsystem: childhood training. The relative weights of these factors lead to patterns. By relating these to a performance criterion at the age of peak performance, particularly promising developmental patterns may be identified. 159 former Swiss football talents were retrospectively interviewed about their career, and the data analysed using the LICUR method (Bergman, Magnusson, \& El-Khouri, 2003). Two early career patterns were identified as having a favourable influence on adult performance. Both are characterised by an above-average amount of in-club training. One pattern also exhibits an aboveaverage amount of informal football played outside the club, the other above-average scores for activity in other sports. Hence comprehensive training and practice inside and outside the club form the basis for subsequent football expertise.

Key words: early specialisation, talent promotion, talent development, personoriented approach, LICUR method 


\section{Introduction}

The path from a promising football talent to a professional player is a long one, and many factors contribute to the success or failure of a professional football career (Baker, Horton, Robertson-Wilson, \& Wall, 2003). Various studies indicate that the ground is prepared decisively in childhood, and corresponding omissions are difficult to make up for (e.g. Ford, Ward, Hodges, \& Williams, 2009).

This paper looks at the example of football to investigate whether specialisation in a sport is more effective with regard to adult performance when first promoting young talents (in childhood), or whether it is better to promote a broad range of different sports. This question is the subject of controversy in the literature. Proponents of early specialisation (e.g. Ericsson, Krampe, \& Tesch-Römer, 1993) face advocates of the broad promotion of multiple sports (e.g. Côté, Horton, MacDonald, \& Wilkes, 2009). A key reason for the mixed findings is probably that existing studies attempt to explain subsequent success or failure by univariate means based on the General Linear Model (GLM). They do not therefore allow for the complexity of human development. Theoretical considerations about how human development progresses (cf. overview by Lerner, 2006) suggest that talent development should be examined as a whole. Following Magnusson (1990), we assume a person-oriented or systemic picture of development which focuses on the human-environment system. This system is divided into various subsystems, consisting of several interacting factors (Bergman \& El-Khouri, 2003). The different level of these so-called operating factors leads to observable patterns which can be summarised as types of similar patterns. This approach has far-reaching methodological consequences, because the systemic interaction between several variables means that the relationships can no longer be 
assumed to be linear and the GLM therefore no longer applies. Instead, pattern analyses (e.g. Trost \& El-Khouri, 2008) are used to implement the person-oriented approach, revealing common developmental patterns and the way in which these are connected with success in sports.

\section{Training to become an expert}

With his expert performance approach, Ericsson (2003b, 2007, 2008) provides an explanation for expertise that is determined by the environment: years of targeted practice, known as deliberate practice (Ericsson, 2003a), ultimately lead to expertise. The term deliberate practice is used "for the individualized training activities especially designed by a coach or teacher to improve specific aspects of an individual's performance through repetition and successive refinement" (Ericsson \& Lehmann, 1996, p. 278-279). Concerning the amount of deliberate practice that is necessary, the 10-year rule (e.g. Simon \& Chase, 1973), and subsequently the 10,000-hour rule, have been suggested as minimum requirements for achieving expertise (Ericsson et al., 1993) and they have been repeatedly confirmed for sports (cf. e.g. Hodge \& Deakin, 1998; Starkes, Helsen, \& Jack, 2001; Young \& Salmela, 2002). Experts undergo a greater volume of training than amateurs and begin deliberate practice earlier on (Ericsson \& Lehmann, 1996).

Studies of team sports (e.g. Helsen, Starkes, \& Hodges, 1998) have shown that the process of practising must be examined more carefully in these sports, because the conditions that exist while training as a team are different and "playing" is not consistent with the conditions for deliberate practice. Côté, Baker and Abernethy (2003) distinguish four types of practice processes: free play, deliberate play, structured practice und deliberate practice. Free play is characterised by process 
orientation (without controlling the process) and joy in the activity. Moving to deliberate practice, these dimensions gradually shift towards the goal of improving performance, result orientation and constant monitoring of the process. Assigning practice processes to these categories is not easy, and the boundaries between them are not sharply defined.

Côté (1999) emphasises that the ratio of free play to deliberate practice changes as a function of age. The first phase of a career (sampling years, approx. 6 to 13 years old) is typified by a high proportion of deliberate play. Côté et al. (2003) also demonstrate that during this career phase, many other sports and games are also tried (sampling) and the sport ultimately chosen is usually not yet known. Within a single sport or game, training should be varied and not too highly specialised (diversification). During the first phase of a career in competitive sports, play, sampling and diversification constitute a training programme that can be described as interdisciplinary, general promotion and thus the antithesis of deliberate practice.

This outlines a central debate within talent research: does early, structured specialisation in a particular type of sport lead to later success, or is a broad promotion of talent more effective? Findings presented by Carlson (1988), Côté, Horton, MacDonald and Wilkes (2009), Stevenson (1990) or by Vaeyens, Güllich, Warr and Philippaerts (2009) suggest that early specialisation is not helpful in promoting top performance later in life. Sampling during the early career phase can optimise the selection of the appropriate sport. A child selects the sport that best fits its own predisposition (principles of multiple sampling and functional matching). In addition, the varied stimuli may promote motor development, which would benefit later performance in the principal sport (later) chosen (Vaeyens et al., 2009). Côté, Baker and Abernethy (2007) discuss the advantages of sampling based on the 
transfer of skills and abilities in the field of movement, perception, concepts (strategies or rules) and physiological conditions. However some of the authors also concede that the question of specialisation must be viewed separately for individual sports and that there are indeed sports for which early specialisation is essential (e.g. gymnastics, figure skating and swimming, but also football). Thus some research results also speak for early specialisation within the targeted sport (e.g. Law, Côté, \& Ericsson, 2007; Ward, Hodges, Williams, \& Starkes, 2008; Williams \& Reilly, 2000). The Developmental Model of Sport Participation (DMSP) attempts to integrate specialisation and general interdisciplinary promotion, and points to two paths leading to top performance in adulthood. Depending on the type of sport and its demands, both elite performance through specialization and elite performance through sampling can lead to expertise (Côté et al., 2007, p. 197). Ford et al. (2009) have applied the model to football and put forward the early engagement hypothesis: both a high level of in-club training (deliberate practice) and a high level of free playing are needed in order to be successful later. Sampling other sports, on the other hand, has no positive effect on later performance in football (Ford et al., 2009).

\section{Talent development from a person-oriented perspective}

Questions about talent promotion are about the process of human development, raising issues in the field of developmental science. In recent times, the focus of talent research has tended to move away from talent selection, towards talent development (Reilly, Williams, \& Richardson, 2008). However talent research has so far failed to integrate the dynamic-interactionist concepts of development which have dominated developmental science in recent years (cf. e.g. Lerner, 2006; Magnusson \& Stattin, 2006) in its treatment of this issue. Instead, today's studies are dominated, 
both in theoretical and methodological respects, by variable-centred approaches (Williams \& Reilly, 2000). However these have various limitations, because interactions between variables are not adequately taken into account. From a dynamic-interactionist perspective, human development occurs by means of various (reciprocal) interactions. If in addition one assumes an integral perspective of human development (e.g. Magnusson \& Cairns, 1996), then the person-oriented perspective becomes a key element (Bergman \& Magnusson, 1997).

In order to reduce the complexity of the entire person-environment system, with a view to making it theoretically and methodologically implementable, the overall system can be divided into various subsystems, each contributing to the system as a whole. Thus research can investigate a single subsystem and the interactions between the variables within it, whereby the variables chosen are fundamentally similar to those used in variable centred approaches. Means of compensation exist between the various factors (Meylan, Cronin, Oliver, \& Hughes, 2010). Such compensation can be mapped using person-oriented analytical tools. The interacting variables of a (sub-) system are referred to as operating factors (Bergman et al., 2003).

The central assumptions of the person-oriented approach suggest that different individuals function and develop differently. Inter-individual differences can be identified via differences in the organisation of operating factors, for example (Bergman et al., 2003). It is assumed here that processes are not accidental, but occur in a specific way within organised structures and principles, with a view to maximising their contribution to the overall system. The "organisation" of the operating factors leads to specific patterns. Only a limited number of particularly 
frequent patterns (known as common types) are observed, since only a limited number of conditions are optimal for the overall system (Bergman \& El-Khouri, 2003). In studies based on an integrative model, the first question to be answered is which operating factors are relevant to a (sub-)system. When examining the functionality of early specialisation vs. generalised promotion in childhood for subsequent top performance, a person-oriented perspective looks for factors directly influencing the motor/athletic development and thus the subsystem childhood training.

\section{Method}

\section{Sample}

Expertise research (using a retrospective approach) (Ericsson, 1996) represents an economical means of collecting data on long periods of development. The aim is to reconstruct individual career paths so as to draw conclusions about factors that are relevant to a successful career. The present study uses this approach.

Players were investigated, who had formerly played for a Swiss national youth team. A total of 346 players were found who had been born between 1981 and 1987 and who had played at least once on a U16 to U21 national youth team. This population of players was sent a paper questionnaire by post. 159 players completed the questionnaire, corresponding to a return rate of $46.0 \%$. A comparison of selected variables (esp. age and number of matches played) shows that the sample and the population from which it is drawn do not differ significantly from each other. This means that the sample is, as far as can be determined, representative of the total population. The heterogeneity of the adult performance (from the Swiss national team to players who ended their career at a young age) allows connections between the long-term training programme and the level of adult performance actually attained 
to be examined. Players were divided into four levels of adult performance based on the criteria level of current team at age of 22 years (22 was the age of the youngest cohort at the time of measurement) and games played on U19 to U21 national youth teams (cf. Table 1).

\section{Table 1}

The questionnaire covered a long period of their lives and some events lay in the distant past. It was therefore only possible to collect data on events that were remembered sufficiently well, which is the case for the volume of training (Helsen et al., 1998; Hodges \& Starkes, 1996; Janson, 1990). The study has received approval from the Ethics Committee of the Faculty of Human Sciences of the University of Bern.

\section{Operationalisation}

The study focuses on the question of training programmes in childhood (up to the age of 12) at the start of the respondents' sporting career. The relevant operating factors for this subsystem can be deduced from the theoretical considerations. In determining the amount of training, a distinction was made between hours spent training in the club and in free play outside the club. Since retrospective studies can only reconstruct the contents of the training sessions very incompletely, we did not attempt to do so. However, supervised in-club training can be assigned more to the category of structured practice and deliberate practice, whereas the time spent training in free play outside the club (without an instructor) can be assigned more to the field of free play and deliberate play (Côté et al., 2003). The cumulative hours of in-club training therefore represent the first operative factor, while the cumulative hours of free football playing outside the club represent the second factor. All forms 
of training in the field of football are therefore covered. Since a number of studies show that participation in other sports has an influence on how an individual's performance subsequently develops (Côté, 1999; Côté et al., 2003; 2009; Vaeyens et al., 2009), this was included in the analysis as a third factor. Sports involvement outside the field of football was operationalised by means of a factor indicating the duration and intensity of the sports engaged in: the competitive level of the sport (1=no competitions, 2=regional competitions, 3=national competitions, 4=international competitions) was multiplied by the number of years over which the sport was practised. For example, if a player played a game at a regional level for two years, he would receive four points. These points were summed over all sports practised, and four groups were formed: $0=0$ (no other sports practised), $1-5=1$ (low engagement in other sports), $6-10=2$ (moderate engagement in other sports), $>10=3$ (high engagement in other sports). Based on the hypothesis that experts start deliberate practice earlier on (Ericsson \& Lehmann, 1996) and in view of the early engagement hypothesis (Ford et al., 2009), the age of first joining a club was included as a fourth factor for pattern formation. Table 2 provides an overview of the operating factors.

\section{LICUR Method}

The LICUR method (Linking of Clusters after removal of a Residue) is one possible methodological implementation of the person-oriented approach (Bergman et al., 2003). The underlying idea is to create groups (clusters) within a developmental phase, containing players with similar manifestations of the operating factors, and to then observe the individual transitions from one cluster to another in the next phase, or to a specific group with a certain developmental outcome. By determining the 
probability of transition, developmental streams can be identified which occur more or less often than would be expected (Bergman \& El-Khouri, 2003). The LICUR method is carried out in three steps. First, a residual analysis is conducted, determining extreme cases and removing these from the data set, since they would excessively bias the cluster solution. They are later analysed separately. In the second step, phase-specific clusters are formed (cluster analysis) and subjects are assigned to these. In the third step, the clusters are linked over time or via the frequency of subjects making the transition from a cluster to the clusters of a later phase.

The residues were analysed using the Residue module of the statistical package SLEIPNER (Bergman \& El-Khouri, 2002). This compares the patterns of pairs of subjects. Those that do not display any similarity with a predetermined number of other subjects are defined as residues. The distance was measured in the form of the Euclidean distance. Bergman et al. recommend choosing the threshold such that residues do not exceed $3 \%$ of the total sample $(2003$, p. 60$)$. A threshold value of $T=0.8$ was chosen for the analysis. In the second step, it is necessary to determine how many similar cases must be observable in order for a pattern not to be regarded as a residue. In this study, $K=1$ was chosen, meaning that only those subjects were excluded whose pattern was unique. In the present study, 4 residues were identified, which is less than the $3 \%$ limit and seems plausible in terms of content.

The cluster analysis was carried out using the Ward procedure with the distance defined as the squared Euclidean distance, as recommended in the literature for person-oriented approaches (Bergman et al., 2003; Trost \& El-Khouri, 2008). The choice of the best cluster solution was guided by content as well as statistical criteria. The statistical criteria applied were the elbow criterion and the Mojena stopping rule, with a threshold of 2.75 (Everitt, 2011, p. 95). Having determined the number of 
clusters, a partitioning cluster analysis was carried out using SLEIPNER's Relocate module ( $k$-means method) which allowed the explained error sum of squares (ESS) of the overall solution to be increased (Bergman \& El-Khouri, 2002).

The analysis of the individual developmental streams was carried out using SLEIPNER's Exacon module (Bergman \& El-Khouri, 2002). The number of transitions from the clusters to specific developmental outcomes are counted and checked for significant deviations compared with the expected number $(p<.05)$ by means of a significance test based on the Fisher test and a hypergeometric distribution (Bergman \& El-Khouri, 2003, p. 90). Paths that occur more often than would be expected assignment are described as developmental types, those that occur less often or not at all are called developmental anti-types.

\section{Results}

\section{Operating factors}

Table 2 provides an overview of the descriptive statistics for the operating factors across the entire sample and across the individual clusters.

\section{Table 2}

Comparing the hours of in-club training with the total hours of training in free play outside the club, the latter is found to be 2.5 times higher, underscoring the great importance of free play and deliberate play in childhood. By the age of 12 , the football players in the sample had already accumulated a quarter of their 10,000 hours through free playing, however the amount does vary considerably. The level of activity in other sports is surprisingly low overall. The mean index is 0.81 , where 0 means no other sports, and 1 means a few other sports were performed. On 
average, involvement in club football started at the age of 6 . None of the players started training in a club later than the age of 11.

\section{Patterns}

The cluster analysis led to a solution involving five patterns with an explained ESS of $54.89 \%$, which does not quite meet the $2 / 3$ criterion (Bergman et al., 2003, p. 89) but is nevertheless satisfactory in view of the high degree of homogeneity of the clusters and in terms of their contents. In addition, the solution was checked for a lack of structure in the data ${ }^{1}$ using SLEIPNER's Simulate module (Bergman \& El-Khouri, 2002). The corresponding $t$-test was significant $(t(19)=7.21, p<.05, d=2.28)$. Each cluster has a specific profile (z-scores) in terms of its operating factors (cf. Figure 1). A highly populated cluster ( $n=45)$ of average players (Cluster 1 ) is found, which does not deviate substantially from the mean value for all players in any of the factors. Cluster $2(n=43)$ is characterised by joining a club at a comparatively late age, and a below-average number of training hours, and is there for labelled football abstainers. Cluster $3(n=21)$ is characterised particularly by an above-average score for nonfootball activities, and is therefore labelled poly-sportive players. Beyond this, members of this cluster joined their clubs at a young age. This early club membership and an above-average number of training hours within the club is also found in Clusters $4(n=19)$ and $5(n=23)$. However these differ in terms of the sports activities pursued outside the football club. Players in Cluster 4 played less football than average, but pursued other sports intensively, which is why they are labelled poly-sportive club players. The players in Clusters 5 played more football than

\footnotetext{
${ }^{1}$ The explained ESS of the original 5-cluster solution is compared with the explained ESS of - in this case -205 -cluster solutions with randomly modified data sets, using the $t$-test. If a difference emerges, the cluster structure can be assumed to actually exist.
} 
average during leisure hours and engaged in few other sports. They are therefore called specialised club players.

\section{Figure 1}

\section{Developmental types and anti-types}

In terms of promoting young talents, we are primarily interested in the developmental paths leading to the highest level of performance in adulthood. Two developmental types can be distinguished, each (at least) twice as likely to achieve top-level performance as would be expected: from the poly-sportive club players and the specialised club players (cf. Figure 1). The poly-sportive club players played less football than average alongside their in-club training, but were more active in other sports than the average. In terms of the transfer of skills, it is worth looking at this group's commitments outside the field of football. 10 of the 19 players engaged in games as their second sport ( $n=8$ tennis, $n=1$ each handball and basketball). Three players were involved in athletics; the rest were distributed among other sports. With all five players who engaged in a third sport, that sport was always a game.

Furthermore a developmental antitype is found for the highest level of performance: the average players (Cluster 1 ) were 3.4 times less likely to become top-class players than would otherwise be expected.

\section{Analysis of residues}

From a theoretical point of view, the residues are on the boundary between actual patterns and ones that are only theoretically conceivable. These boundaries are important for the promotion of young talents because exceptional performance can be assumed to come about through exceptional patterns. Figure 2 shows the profile of the $z$-scores for the four residues. Only Residue 201 achieved a top level of 
performance as an adult. This player is characterised by an extremely high amount of free playing ( $z=4.94)$ and an above-average activity in other sports $(z=2.06)$. Apart from specialising in football, he played a lot of basketball. The profile of Residue 99 resembles that of Residue 201. In contrast to Reside 201, however, Residue 99 only reached the lowest level of performance. Residues 15 and 80 also display similar profiles. Both trained well above average in their clubs and are average concerning other operating factors. Residue 80 made it to an adult performance level of three, Residue 15 to a level of two.

\section{Figure 2}

\section{Discussion}

Two developmental types have been found to lead from the first career stage to the top level of performance in adulthood: the specialised club players (Cluster 5) display an above-average amount of in-club training and also more than the average amount of free playing of football outside the club (specialization), whereas their commitment to other sports is below the already low average of the population. Poly-sportive club players (Cluster 4) also have above-average scores for in-club training, but a slightly lower-than-average level of free playing of football. Since both types display an above-average amount of in-club training and the commitment to other sports is comparatively low throughout the entire sample (cf. Table 1), the emphasis lies on specialisation. It appears that special effort is required already in childhood in order to achieve a high level of football performance at the age of peak performance. The analysis of the patterns suggests that commitment to other sports can also promote later top-level performance. A smaller amount of free football playing can possibly be made up for by engaging in other sports. 
The analysis of the residues confirms the findings. Residues 99 and 201 display a high level of free play as well as above-average commitment to other sports (in both cases basketball) and thus suggest promising patterns. One of the players (201) achieved the top level of performance; the other ended his football career at the age of 18 due to a death in the family. The other two residues are characterised by above-average levels of in-club training, with average scores on the other factors, and subsequently achieved levels of two and three respectively. Intensive in-club training without considerable training outside the club does not appear to suffice for achieving top performance levels. This finding agrees with the pattern of the developmental antitype (cf. Cluster 1).

The path to the very top is difficult in football, for a variety of reasons: on the one hand, the game makes complex demands on players; on the other hand it is extremely popular, which leads to a high level of professionalisation in the infrastructure for promoting young talents, a higher level of performance (already apparent in the field of young talents) and a high density of performance at all levels. Since the promising patterns emerging from the pattern analyses we have presented display a clear focus on football from early childhood, this difficult path seems to be most successful when training starts young and is closely linked to football. Dynamic-interactionist development theories are best able to do justice to the demands of modern definitions of talent, which are based on a dynamically broad concept of talent (cf. for example Williams \& Reilly, 2000). From a holistic point of view, this leads to systemic concepts of development. However, this in turn means that using evaluation procedures which are guided by the GLM will result in a mismatch between theory and methods (Bergman \& Andersson, 2010), since such relationships cannot be assumed to be linear (Magnusson \& Stattin, 2006). Even 
though the far-reaching, dynamic-interactionist conceptual framework is somewhat overstretched as a basis for the rather narrow question posed in this paper, we are convinced that future studies on the promotion of young talents would benefit from investigating such issues from the perspective of systemic development theories and resorting to corresponding methodological implementations. 


\section{Reference List}

Baker, J., Horton, S., Robertson-Wilson, J., \& Wall, M. (2003). Nurturing Sport Expertise: Factors Influencing the Development of Elite Athlete. Journal of Sports Science and Medicine, 2, 1-9.

Bergman, L. R., \& Andersson, H. (2010). The Person and the Variable in Developmental Psychology. Journal of Psychology, 218(3), 155-165.

Bergman, L. R., \& El-Khouri, B. M. (2002). SLEIPNER - a statistical package for pattern-oriented analyses: User Manual. Unpublished manuscript, Stockholm University.

Bergman, L. R., \& El-Khouri, B. M. (2003). A Person-Oriented Approach: Methods for Today and Methods for Tomorrow. New Directions for Child and Adolescent Development, 101, 25-38.

Bergman, L. R., \& Magnusson, D. (1997). A Person-Oriented Approach in Research on Developmental Psychopathology. Development and Psychopathology, 9, 291319.

Bergman, L. R., Magnusson, D., \& El-Khouri, B. M. (2003). Studying Individual Development in an Interindividual Context: A Person-Oriented Approach. Paths Through Life: Vol. 4. Mahwah, New Jersey: Erlbaum.

Carlson, R. C. (1988). The socialization of elite tennis players in Sweden: An analysis of the players' backgrounds and development. Sociology of Sport Journal, 5(3), 241-256.

Côté, J. (1999). The Influence of the Family in the Development of Talent in Sport. The Sport Psychologist, 13(Special Issue), 395-417. 
Côté, J., Baker, J., \& Abernethy, B. (2003). From Play to Practice: A Developmental Framework for the Acquisition of Expertise in Team Sports. In J. L. Starkes \& K. A. Ericsson (Eds.), Expert Performance in Sports. Advances of Research on Sport Expertise (pp. 89-95). Champaign IL: Human Kinetics.

Côté, J., Baker, J., \& Abernethy, B. (2007). Practice and Play in the Development of Sport Expertise. In G. Tenenbaum \& R. C. Eklund (Eds.), Handbook of Sport Psychology (3rd ed., pp. 184-202). New Jersey: Hoboken.

Côté, J., Horton, S., MacDonald, D., \& Wilkes, S. (2009). The Benefits of Sampling Sports During Childhood. Physical \& Health Education Journal, 74, 6-11.

Ericsson, K. A. (1996). The Road to Excellence. The Acquisition of Expert Performance in the Arts and Sciences, Sports and Games. Mahwah, New Jersey: Lawrence Erlbaum Associates.

Ericsson, K. A. (2003a). Development of Elite Performance and Deliberate Practice: An Update from the Perspective of the Expert Performance Approach. In J. L. Starkes \& K. A. Ericsson (Eds.), Expert Performance in Sports. Advances of Research on Sport Expertise (pp. 49-81). Champaign, IL: Human Kinetics.

Ericsson, K. A. (2003b). How the Expert Performance Approach Differs from Traditional Approaches to Expertise in Sport: In Search of a Shared Theoretical Framework for Studying Expert Performance. In J. L. Starkes \& K. A. Ericsson (Eds.), Expert Performance in Sports. Advances of Research on Sport Expertise (pp. 371-403). Champaign, IL: Human Kinetics.

Ericsson, K. A. (2007). Deliberate practice and the modifiability of body and mind: toward a science of the structure and acquisition of expert and elite performance. International Journal of Sport Psychology, 38 (1), 4-34. 
Ericsson, K. A. (2008). Deliberate Practice and Acquisition of Expert Performance: A General Overview. Academic Emergency Medicine, 15(11), 988-994.

Ericsson, K. A., Krampe, R. T., \& Tesch-Römer, C. (1993). The Role of Deliberate Practice in the Acquisition of Expert Performance. Psychological Review, 100(3), 363-406.

Ericsson, K. A., \& Lehmann, A. C. (1996). Expert and Exceptional Performance: Evidence of Maximal Adaptation to Task Constraints. Annual Review of Psychology, 47, 273-305.

Everitt, B. S. (2011). Cluster analysis (5th ed.). Chichester: Wiley-Blackwell.

Ford, P., Ward, P., Hodges, N. J., \& Williams, A. M. (2009). The role of deliberate practice and play in career progression in sport: the early engagement hypothesis. High Ability Studies, 20, 65-75.

Helsen, W. F., Starkes, J. L., \& Hodges, N. J. (1998). Team sports and the theory of deliberate practice. Journal of Sport \& Exercise Psychology, 20, 12-34.

Hodge, T., \& Deakin, J. (1998). Deliberate practice and expertise in the martial arts: The role of context in motor recall. Journal of Sport and Exercise Psychology, 20, 260-279.

Hodges, N.J. \& Starkes, J.L. (1996). Wrestling with the Nature of Expertise: A Sport Specific Test of Ericsson, Krampe and Tesch-Romer's (1993) Theory of "Deliberate Practice". International Journal of Sport Psychology, 27, 400-424.

Janson, C.-G. (1990). Retrospective data, undesirable behavior and the longitudinal perspective. In D. Magnusson \& L. Bergman (Hrsg.), Data quality in longitudinal research. 3rd Workshop: Papers (S. 100-121). Cambridge: Cambridge University Press. 
Law, M., Côté, J., \& Ericsson, K. A. (2007). Characteristics of expert development in rhythmic gymnastics: A retrospective study. International Journal of Sport and Exercise Psychology, 5, 82-103.

Lerner, R. M. (2006). Developmental Science, Developmental Systems, and Contemporary Theories of Human Development. In W. Damon (Ed.), Handbook of Child Psychology (6th ed., pp. 1-17). Hoboken, N.J., Chichester: Wiley; John Wiley.

Magnusson, D. (1990). Personality development from an interactional perspective. In L. A. Pervin (Ed.), Handbook of personality: Theory and research (pp. 193-222). New York, NY: Guilford Press.

Magnusson, D., \& Cairns, R. B. (1996). Developmental Science: Toward a Unified Framework. In R. B. Cairns, G. H. Elder, \& E. J. Costello (Eds.), Developmental science (pp. 7-30). Cambridge: University Press.

Magnusson, D., \& Stattin, H. (2006). The Person in Context: A HolisticInteractionistic Approach. In W. Damon (Ed.), Handbook of Child Psychology (6th ed., pp. 400-464). Hoboken, N.J., Chichester: Wiley; John Wiley.

Meylan, C., Cronin, J., Oliver, J., \& Hughes, M. (2010). Talent Identification in Soccer: The Role of Maturity Status on Physical, Physiological and Technical Characteristics. International Journal of Sports Science \& Coaching, 5(4), 571592.

Reilly, T., Williams, A. M., \& Richardson, D. (2008). Talent Identification and Development in Football. In R. Fisher \& R. Bailey (Eds.), Talent Identification and Development. The Search for Sporting Excellence (pp. 183-199). Berlin: ICSSPE. 
Simon, H. A., \& Chase, W. G. (1973). Skill in Chess. American Scientist, 61(4), 394403.

Starkes, J. L., Helsen, W., \& Jack, R. (2001). Expert Performance in Sport and Dance. In R. N. Singer, H. A. Hausenblas, \& C. M. Janelle (Eds.), Handbook of Sport Psychology (2nd ed., pp. 174-201). New York.

Stevenson, C. L. (1990). The athletic career: Some contingencies of sport specialization. Journal of Sport Behavior, 13, 103-113.

Trost, K., \& El-Khouri, B. M. (2008). Mapping Swedish Females' Educational Pathways in Terms of Academic Competence and Adjustment Problems. Journal of Social Issues, 64(1), 157-174.

Vaeyens, R., Güllich, A., Warr, C. R., \& Philippaerts, R. (2009). Talent identification and promotion programmes of Olympic athletes. Journal of Sports Sciences, 27(13), 1367-1380.

Ward, P., Hodges, N. J., Williams, A. M., \& Starkes, J. L. (2008). Deliberate practice and expert performance. Defining the path to excellence. In M. A. Williams \& N. J. Hodges (Eds.), Skill acquisition in sport. Research, theory and practice (pp. 231258). London: Routledge.

Williams, A. M., \& Reilly, T. (2000). Talent identification and development in soccer. Journal of Sports Sciences, 18, 657-667.

Young, B. W., \& Salmela, J. H. (2002). Perceptions of training and deliberate practice of middle distance runners. International Journal of Sport Psychology, 33, 167181. 
Table 1. Description and distribution of the four levels of adult performance

\begin{tabular}{lllcc}
\hline $\begin{array}{l}\text { Short } \\
\text { Description }\end{array}$ & Description & Definition & Frequency & Percentage \\
\hline Level 1 & $\begin{array}{l}\text { Players at international } \\
\text { level }\end{array}$ & $\begin{array}{l}\text { SL with more than 20 games for } \\
\text { NYT U19 to U21 and NT-A }\end{array}$ & 24 & 15.1 \\
\hline Level 2 & $\begin{array}{l}\text { Players at top national } \\
\text { level }\end{array}$ & $\begin{array}{l}\text { SL with up to 20 games for NYT } \\
\text { U19 to U21 }\end{array}$ & 42 & 26.4 \\
\hline Level 3 & $\begin{array}{l}\text { Players at national } \\
\text { level }\end{array}$ & $\begin{array}{l}\text { CL and SL with no games for } \\
\text { NYT U19 to U21 }\end{array}$ & 59 & 37.1 \\
\hline Level 4 & Players at regional level & First league or below & 34 & 21.4 \\
\hline Total & & & 159 & 100.0 \\
\hline SL = Super League; NYT = National Youth Team; NT-A = National Team A; CL = Challenge League
\end{tabular}


Table 2. Descriptive statistics for the operating factors (up to 12 years old)

\begin{tabular}{lccccccccc}
\hline & \multicolumn{10}{c}{ Operating factors $^{1}$} \\
\cline { 2 - 11 } & \multicolumn{2}{c}{1} & \multicolumn{1}{c}{2} & & 3 & & 4 \\
\cline { 2 - 10 } & 9 & $s$ & $M$ & $s$ & $M$ & $s$ & $M$ & $s$ \\
\hline Overall & 966.9 & 287.1 & 2535.5 & 1277.3 & 0.81 & 1.06 & 6.07 & 1.31 \\
\hline Cluster 1 $(n=45)$ & 971.6 & 185.2 & 2056.9 & 748.0 & 1.27 & 0.45 & 5.40 & 0.75 \\
Cluster 2 $(n=43)$ & 701.9 & 168.5 & 2222.7 & 832.6 & 1.49 & 0.83 & 7.44 & 1.05 \\
Cluster 3 $(n=21)$ & 919.1 & 150.3 & 3175.0 & 1157.8 & 3.62 & 0.50 & 5.24 & 0.94 \\
Cluster 4 $(n=19)$ & 1311.7 & 206.3 & 1364.3 & 612.1 & 2.58 & 0.90 & 6.21 & 1.18 \\
Cluster 5 $(n=23)$ & 1212.1 & 280.8 & 4440.4 & 1062.0 & 1.22 & 0.52 & 5.48 & 0.90 \\
\hline
\end{tabular}

${ }^{1}$ Operating factors:

$1=$ Cumulative number of training hours, club

$2=$ Cumulative number of training hours, free play

$3=$ Index of sports activities alongside football $(0=$ no other sports, $1=$ few other sports, $2=$ =moderate amount of other sports, 3=multisport childhood)

$4=$ Age of beginning training in club (years) 
Cluster $1(n=45) \quad H C=0.63$

Average players

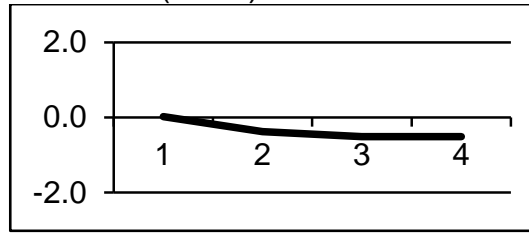

Football abstainers

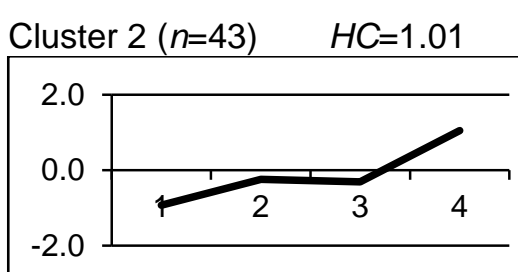

Poly-sportive

players

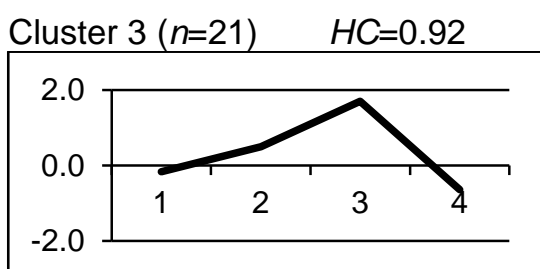

Poly-sportive club players

Specialised club players
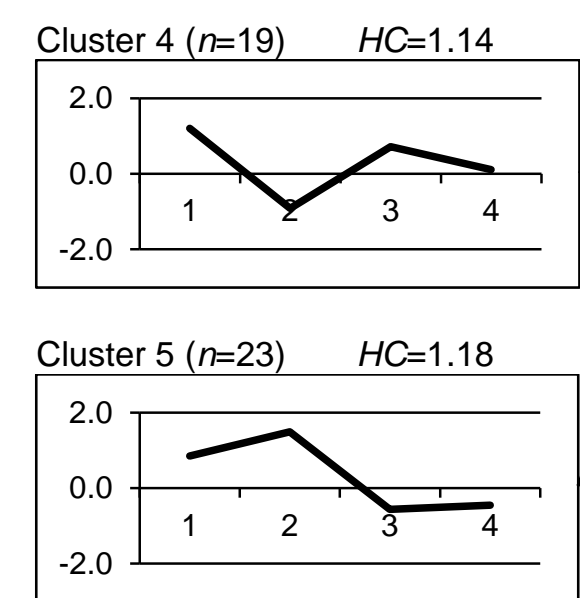

Operating factors:

$1=$ Hours of training, club

$2=$ Hours of training, free play

3 = Sports activity alongside football

4 = Age of beginning training in club

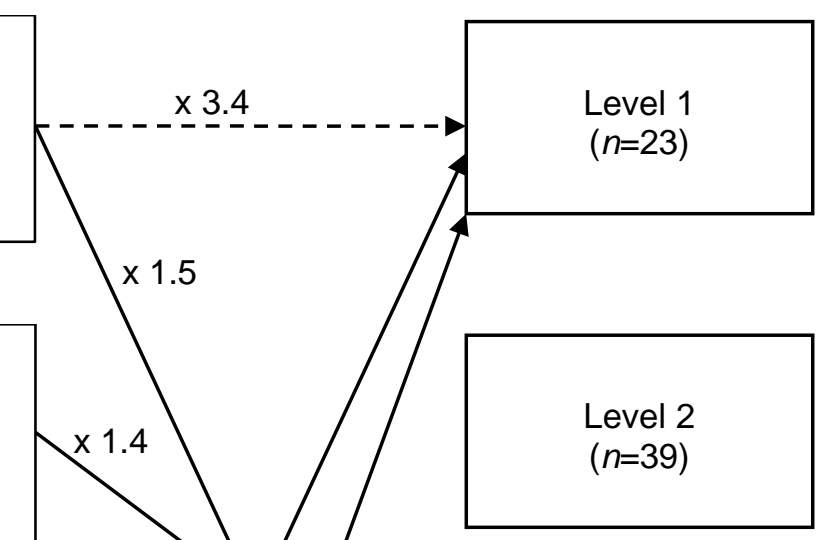

\section{of Performance}

$(n=39)$

Level 3

$(n=56)$

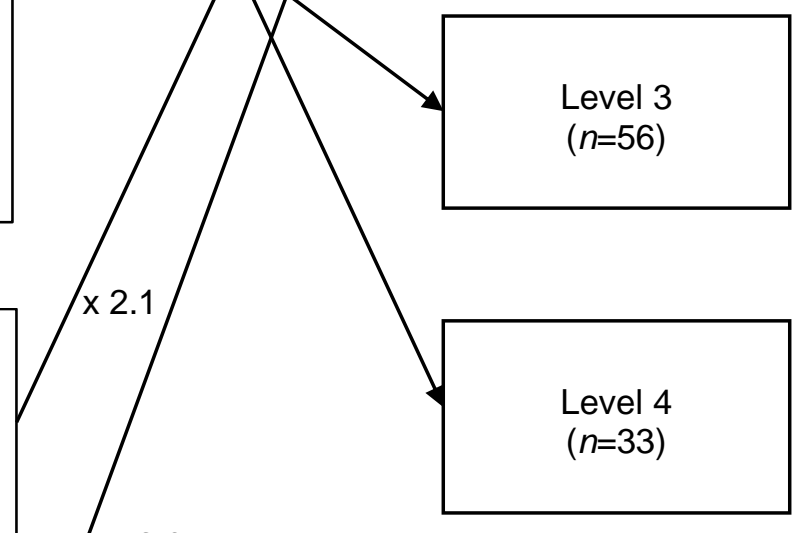

$\times 2.0$

$H C=$ Homogeneity Coefficient (average squared Euclidean distance within cluster)

$\longrightarrow$ sig. developmental type

$\longrightarrow$ sig. developmental anti-type ${ }^{1}$

${ }^{1}$ The numbers given refer to the factor by which a particular path was more or less likely to be followed than would be expected. 
Initial phase (up to 12 years old)

Residue No. $15 \rightarrow$ Level 2

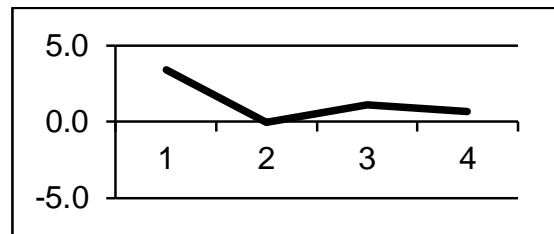

Residue No. $80 \rightarrow$ Level 3

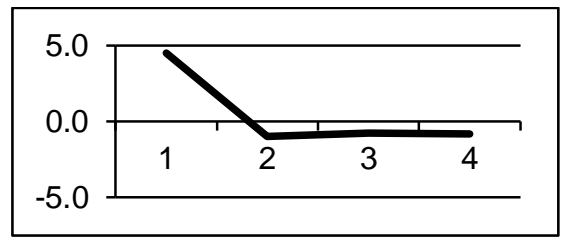

$1=$ Hours of training, club

$2=$ Hours of training, free play

3 = Sports activity alongside football

4 = Age on beginning training in club
Residue No. $99 \rightarrow$ Level 4

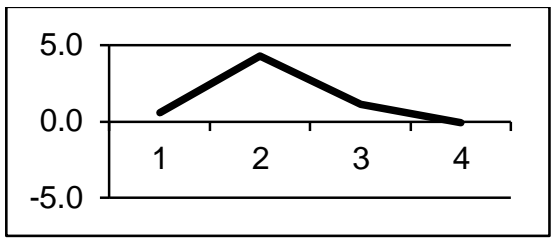

Residue No. $201 \rightarrow$ Level 1

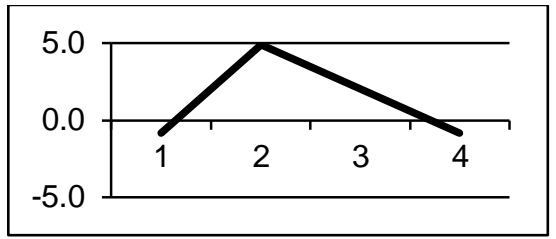

